that nesting Canada Geese exhibit varying degrees of tolerance towards ducks near the nest site. Dow found a Mallard nesting "within a few feet" of a nesting Canada Goose on a haystack. ${ }^{3}$ Mather reported that nests of a wild Mallard and a wild Canada Goose were located only 1.2 $\mathrm{m}$ apart on a pond in Allentown, Penn. ${ }^{6}$ Ewaschuk noted ducks walking in close proximity to incubating geese with no apparent response from the goose or gander. ${ }^{4}$ However, Cooper observed that aggressive action was taken by nesting geese (B.c. maxima) towards all ducks near their nest. ${ }^{2}$

My observation shows that ducks can nest in close proximity to Canada Geese. It also supports the conclusion of Giroux who suggested that nesting ducks were attracted to manmade islands used by nesting geese. ${ }^{5}$ He reported that ducks, especially Pintails and Mallards, benefit from a commensalistic association with Canada Geese in that geese are adept at keeping predators away from the vicinity of their nests, and consequently from nearby nesting ducks.

The investigation was done under the auspices of Ducks Unlimited (Canada). R. W. Boychuk supervised the study. J. F. Giroux provided valuable suggestions and criticisms of this manuscript. C. L. Glenn, D. F. Hackett, and R. C. Rounds provided helpful comments.

'BRACE, R. K. 1972. A study of the nesting ecology, productivity, and mortality of Canada Geese at Waterhen Marsh, Saskatchewan. M.Sc. Thesis, Univ. Saskatchewan, Regina Campus, Regina, Saskatchewan. 162 pp.

COOPER, J. A. 1978. The history and breeding biology of the Canada Goose of Marshy Point, Manitoba. Wildl. Monogr. 61. 87 pp.
${ }^{3}$ DOW, J. S. 1943. A study of nesting Canada Geese in Honey Lake, Valley California, Calif. Fish and Game 29:3-18.

${ }^{4}$ EWASCHUK, E. 1970. The influence of territorial behaviour on nesting success in a population of Canada Geese. M.Sc. Thesis, Univ. Alberta, Edmonton. $60 \mathrm{pp}$.

${ }^{5}$ GIROUX, J. F. 1979. Use of artificial islands by nesting waterfowl. M.Sc. Thesis, Univ. Alberta. Edmonton. 98 pp.

${ }^{6}$ MATHER, T. N. 1978. Canada Goose takes over mallard nest. Wilson Bull. 90(4):646-7.

\section{COMMON GRACKLE WINTERS AT BRANDON, MANITOBA}

MAMIE MCCOWAN, 1415 - 8th Street, Brandon, Manitoba R7A $3 Z 6$.

When I have noticed in Christmas Bird Counts, species that usually go south for the winter, I have wondered how many of these birds would survive severe January weather.

Early in December 1979 a Common Grackle was noticed in this neighborhood and has been seen through the winter. It frequented the yard of my neighbor Barbara Robinson, who has a bird feeding station and good tree and shrub cover. It came to the feeding tray for sunflower and other seeds. With the approach of spring the grackle has been heard every day piping its song. Now at the end of March the juncos are back and the grackle is still with us. Hearing its song when I first go out in the morning has brought to mind these lines of a hymn - "Morning has broken like the first morning, blackbird has spoken like the first bird". 